\title{
Evaluation of the Global Multi-Resolution Terrain Elevation Data 2010 (GMTED2010) Using ICESat Geodetic Control
}

\author{
Claudia C. Carabajal*a, David J. Harding ${ }^{\mathrm{b}}$, Jean-Paul Boy ${ }^{\mathrm{c}}$, Jeffrey J. Danielson ${ }^{\mathrm{d}}$, Dean B. Gesch ${ }^{\mathrm{d}}$ \\ and Vijay P. Suchdeo ${ }^{a}$ \\ ${ }^{a}$ Sigma Space Corporation @ NASA/GSFC, Planetary Geodynamics Laboratory, Code 698, \\ Greenbelt, MD USA 20771; \\ bNASA/GSFC, Planetary Geodynamics Lab., Code 698, Greenbelt, MD USA 20771; \\ ${ }^{\circ}$ EOST-IPGS (UMR 7516 CNRS-UdS), 5 rue Rene Descartes, Strasbourg, FRANCE 67084; \\ ${ }^{d}$ U.S. Geological Survey (USGS), Earth Resources Observation \& Science (EROS), SD USA 57198.
}

\begin{abstract}
Supported by NASA's Earth Surface and Interior (ESI) Program, we are producing a global set of Ground Control Points (GCPs) derived from the Ice, Cloud and land Elevation Satellite (ICESat) altimetry data. From February of 2003, to October of 2009, ICESat obtained nearly global measurements of land topography $\left( \pm 86^{\circ}\right.$ latitudes $)$ with unprecedented accuracy, sampling the Earth's surface at discrete $\sim 50 \mathrm{~m}$ diameter laser footprints spaced $170 \mathrm{~m}$ along the altimetry profiles. We apply stringent editing to select the highest quality elevations, and use these GCPs to characterize and quantify spatially varying elevation biases in Digital Elevation Models (DEMs). In this paper, we present an evaluation of the soon to be released Global Multi-resolution Terrain Elevation Data 2010 (GMTED2010). Elevation biases and error statistics have been analyzed as a function of land cover and relief. The GMTED2010 products are a large improvement over previous sources of elevation data at comparable resolutions. RMSEs for all products and terrain conditions are below $7 \mathrm{~m}$ and typically are about $4 \mathrm{~m}$. The GMTED2010 products are biased upward with respect to the ICESat GCPs on average by approximately $3 \mathrm{~m}$.
\end{abstract}

Keywords: ICESat, Laser Altimetry, Lidar, SRTM, GMTED2010, Digital Elevation Models, DEM, Geodetic Ground Control Points, GCP, Topography.

\section{INTRODUCTION}

A primary contribution of accurate laser altimeter elevation profiles is the independent characterization of systematic and random elevation errors in Digital Elevation Models (DEMs) produced by photogrammetric and Interferometric Synthetic Aperture Radar (SAR) techniques. By conducting this analysis the impact of DEM errors on the scientific and applied uses of the data can be assessed, including determination of elevation change by differencing DEMs acquired from different sources separated in time. The comprehensive, near global coverage across continents provided by NASA's Ice, Cloud and land Elevation Satellite (ICESat) mission enables correction of long-wavelength DEM errors that can not be achieved by other means ${ }^{[1,2]}$. We have used ICEsat data to evaluate the accuracy of the 30 and $90 \mathrm{~m}$ resolution, near-global DEM produced by the Shuttle Radar Topography Mission (SRTM) ${ }^{[3,4,5,6]}$ and the more recent global ASTER (Advanced Spaceborne Thermal Emission and Reflection Radiometer) Global Digital Elevation Model $(G D E M)^{[7]}$. The ICESat mission acquired single-beam, globally distributed laser altimeter profiles between $\pm 86^{\circ}$ using the Geoscience Laser Altimeter Sensor (GLAS) ${ }^{[1,2]}$. Data was collected from February, 2003 to October, 2009 during approximately month long observation periods, three times per year through 2006 and twice per year thereafter. Three lasers were used sequentially during the mission. Data acquired with Laser 2 and 3 are used in this study. These altimetry profiles provide a highly accurate and consistently referenced elevation data set with quantified errors. We select laser altimetry elevation measurements from ICESat to generate Ground Control Points (GCPs) with subdecimeter vertical accuracy and better than $10 \mathrm{~m}$ horizontal accuracy. ICESat waveforms represent the vertical distribution of energy reflected within the laser footprint from vegetation where present, and the ground where illuminated through gaps in any vegetation cover. The footprint diameter was nominally $70 \mathrm{~m}$ for Laser 1 and $50 \mathrm{~m}$ for Laser 2, and the footprints are space ever $170 \mathrm{~m}$ along the profile. Using attributes of the waveforms, we assess the accuracy of Digital Elevation Models (DEM) with respect to the highest elevations, the centroid (average elevation), and lowest elevations observed by ICESat for every laser footprint, and in some cases with respect to the ground identified 
beneath vegetation cover ${ }^{[8]}$ where a distinct, low peak is present in the waveform. Table 1 shows the various ICESat observation periods, their collection dates and estimates of their pointing, horizontal and vertical accuracies. These estimates are based on the results of instrument calibration and validation using ocean scan maneuvers and cross-over analysis. The means and standard deviations are based on long orbit arc $(\sim 1,700 \mathrm{~km})$ solutions ${ }^{[9]}$. The estimates shown in Table 1 correspond to data processed as Release 31.

Table 1. ICESat observation periods, their timelines, transmit energy and long arc accuracy estimates from scan maneuvers and cross-overs. The laser used during each period is indicated by the number in the period designations.

\begin{tabular}{|c|c|c|c|c|c|c|}
\hline $\begin{array}{l}\text { ICESat } \\
\text { Observation } \\
\text { Period } \\
\text { (91-day) } \\
\text { Release } 31\end{array}$ & Start Date & End Date & $\begin{array}{l}\text { Laser } \\
\text { Energy } \\
\text { Corrected } \\
\text { for FOV } \\
\text { Shadowing } \\
\text { Effects (mJ) }\end{array}$ & $\begin{array}{l}\text { Pointing } \\
\text { accuracy } \\
\text { (arcsec) }\end{array}$ & $\begin{array}{l}\text { Long arc } \\
\text { ( 1700 km) } \\
\text { Estimate } \\
\text { Horizontal } \\
\text { Accuracy (m) }\end{array}$ & $\begin{array}{l}\text { Long are } \\
(\sim 1700 \mathrm{~km}) \\
\text { Estimate } \\
\text { Vertical } \\
\text { Accuracy } \\
0.4^{\circ} \text { Slope } \\
(\mathrm{cm})\end{array}$ \\
\hline L2A & $10 / 13 / 2003$ & $11 / 19 / 2003$ & 70.7 & $0.27 \pm 1.64$ & $0.79 \pm 4.77$ & $0.6 \pm 3.3$ \\
\hline L2B & $2 / 17 / 2004$ & $3 / 21 / 2004$ & 45.6 & $0.32 \pm 1.28$ & $0.93 \pm 3.73$ & $0.7 \pm 2.6$ \\
\hline $\mathrm{L2C}^{*}$ & $5 / 18 / 2004$ & $6 / 21 / 2004$ & 12.5 & $0.13 \pm 3.54$ & $0.37 \pm 10.30$ & $0.3 \pm 7.2$ \\
\hline L2D & $11 / 25 / 2008$ & $12 / 17 / 2008$ & 5.4 & $0.59 \pm 2.53$ & $1.72 \pm 7.36$ & $1.2 \pm 5.14$ \\
\hline L2E & $3 / 9 / 2009$ & $4 / 11 / 2009$ & 2.8 & $0.80 \pm 2.75$ & $2.32 \pm 8.01$ & $1.6 \pm 5.59$ \\
\hline L3A & $10 / 3 / 2004$ & $11 / 8 / 2004$ & 63.7 & $0.19 \pm 1.13$ & $0.56 \pm 3.29$ & $0.4 \pm 2.3$ \\
\hline L3B & $2 / 17 / 2005$ & $3 / 24 / 2005$ & 59.1 & $0.02 \pm 1.44$ & $0.07 \pm 4.20$ & $0.1 \pm 2.93$ \\
\hline $\mathrm{L3C}^{*}$ & $5 / 20 / 2005$ & $6 / 23 / 2005$ & 45.5 & $0.10 \pm 1.00$ & $0.29 \pm 2.92$ & $0.2 \pm 2.04$ \\
\hline L3D & $10 / 21 / 2005$ & $11 / 24 / 2005$ & 39.4 & $0.02 \pm 0.98$ & $0.07 \pm 2.86$ & $0.1 \pm 2.0$ \\
\hline L3E & $2 / 22 / 2006$ & $3 / 28 / 2006$ & 34.1 & $0.00 \pm 1.17$ & $0.00 \pm 3.41$ & $0.0 \pm 2.38$ \\
\hline $\mathrm{L3F}^{*}$ & $5 / 24 / 2006$ & $6 / 26 / 2006$ & 30.8 & $0.47 \pm 1.52$ & $1.35 \pm 4.42$ & $1.0 \pm 3.08$ \\
\hline L3G & $10 / 25 / 2006$ & $11 / 27 / 3006$ & 27.1 & $0.02 \pm 1.16$ & $0.07 \pm 3.37$ & $0.1 \pm 2.35$ \\
\hline L3H & $3 / 12 / 2007$ & $4 / 14 / 2007$ & 22.6 & $0.00 \pm 1.48$ & $0.00 \pm 4.29$ & $0.0 \pm 3.0$ \\
\hline L3I & $10 / 2 / 2007$ & $11 / 5 / 2007$ & 20.5 & $0.22 \pm 0.76$ & $0.65 \pm 2.22$ & $0.5 \pm 1.55$ \\
\hline L3J & $2 / 17 / 2008$ & $3 / 21 / 2008$ & 17.7 & $0.21 \pm 1.60$ & $0.62 \pm 4.66$ & $0.4 \pm 3.25$ \\
\hline${\mathrm{L} 3 \mathrm{~K}^{*}}^{*}$ & $10 / 4 / 2008$ & $10 / 19 / 2008$ & 15.6 & $0.05 \pm 1.29$ & $0.15 \pm 3.74$ & $0.1 \pm 2.61$ \\
\hline
\end{tabular}

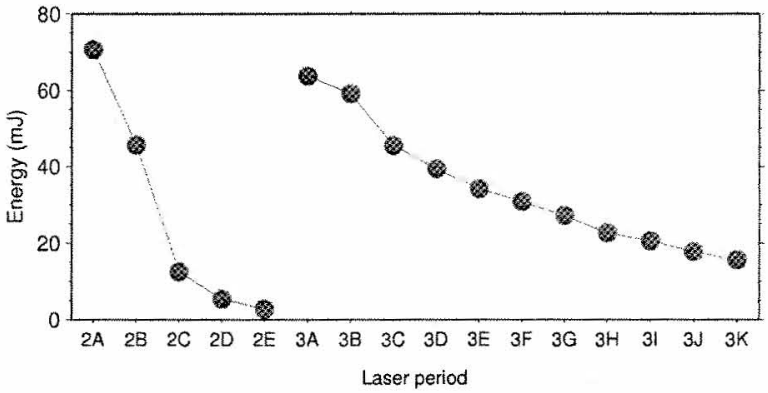

Fig. 1. ICESat average transmit energy (mJ), corrected for receiver field of view (FOV) shadowing effects, for the Laser 2 and 3 observation periods used in this study. Degradation of laser performance caused a more rapid decrease in energy than was expected.

In this paper, we describe our development of an ICESat geodetic ground control point (GCP) database and its use evaluating the Global Multi-resolution Terrain Elevation Dataset 2010 (GMTED2010) in Australia, for 4 of the DEM products that will later be distributed publically. We identify mean biases per ICESat observation period separately, documenting that the ICESat results are highly reproducible, in spite of the effects of instrumental parameters 
characteristic of each operating laser which may introduce small inter-period biases, such as the transmit energy, on the observations (Figure 1).

We apply stringent editing criteria to yield a high quality GCP database. We exclude ICESat data identified as returns from water based on the ENVISAT MERIS Globcover land cover classification ${ }^{[10]}$. ICESat data from clouds is excluded by editing elevations that are above SRTM elevations by more than $50 \mathrm{~m}$. We exclude data where the width of the waveform implies there is a significant height range detected within the laser footprint due to relief (slope and/or roughness of the ground) and/or vegetation cover. The impulse response for GLAS, that is the width of the received waveform from a flat, smooth target, is approximately $7 \mathrm{nsec}(1 \mathrm{~m})$ (the full width at half the peak amplitude) and approximately $17 \mathrm{nsec}(2.5 \mathrm{~m})$ at its base (the width from the start to the end of the waveform signal at a low threshold above the background noise). To obtain highly accurate GCPs we select waveforms with widths from signal start to end less than $5 \mathrm{~m}$, indicating the within-footprint relief is very low and vegetation, if present, is of low stature. We also apply editing based on instrumental parameters. Returns with low received energy are excluded by only using returns with maximum amplitudes greater than 0.15 Volts, and widths $>0.5 \mathrm{~m}$. Saturation broadens, distorts and truncates the received waveforms when the return energy exceeds the receiver's or the digitizer's dynamic range. Although laboratory calibrations developed as a function of receiver gain and observed received energy exist to correct elevations and receive energies, we only keep non-saturated to minimally saturated data. We use data when the saturation index (the number of waveform bins with an amplitude greater than the saturation threshold) is two or less, and the available correction to the elevation is applied for those slightly saturated returns. We minimize data that may be affected by waveform broadening due to incidence angle between the laser beam vector and the normal to the surface slope by excluding data acquired when the laser beam was pointed off from nadir by more than $1^{\circ}$. We also exclude waveforms with pulses narrower than the transmit pulse. Rigorous analysis has shown that for low relief locations the ICESat data meet the accuracy requirements of $6 \mathrm{~m}$ horizontal and $10 \mathrm{~cm}$ vertical (Table 1) ${ }^{[9]}$. This accuracy was somewhat degraded during the laser operating periods where the spacecraft was flying in airplane mode, indicated in Table 1 with an asterisk. However, we expect that our GCPs are of equivalent accuracy for all periods based on the stringent editing criteria applied to the data.

GMTED2010 is a collaborative effort between the U.S. Geological Survey (USGS) Earth Resources Observation and Science (EROS) Data Center in Sioux Falls, South Dakota and the National Geospatial-Intelligence Agency (NGA) ${ }^{[11}$,

${ }^{12]}$. This new global elevation product suite has been generated as a replacement to the 1996 vintage GTOPO30 dataset (30 arc-seconds spacing, or approximately $1 \mathrm{~km}$ ) for topographic data applications at the global and continental scale ${ }^{[13]}$. The accuracy of the GTOPO30 data set was evaluated in a manner similar to that used here, but with a less comprehensive approach using a lower accuracy laser altimeter data set acquired by the Shuttle Laser Altimeter ${ }^{[14,15]}$. GMTED2010 has been generated at three separate resolutions (horizontal post spacing) of 30 arc-seconds (approximately 1 kilometer), 15 arc-seconds (approximately 500 meters), and 7.5 arc-seconds (approximately 250 meters) where supported by the input source data. In addition, there will be seven new raster elevation products produced for each resolution. While executing the aggregation procedures, minimum elevation, maximum elevation, mean elevation, median elevation, standard deviation of elevation, systematic subsample, and breakline emphasis products have been produced. Based on the selected aggregation strategy, a systematic thinning of the full resolution source data was performed to produce the reduced resolution versions at each of the output grid spacings. These new products use the SRTM Digital Terrain Elevation Data (DTED $囚 2$ ) (void-filled) 1 arc-second DEM as its primary source (approximately $70 \%$ of its source) ${ }^{[3,16]}$. Because the GMTED2010 products have been generalized from higher resolution sources than those used in the GTOPO30 production, the new generalized products exhibit more topographic detail than GTOPO30. Upon its distribution, the generalized raster elevation products, spatially referenced metadata, and full dataset documentation will be released with the documentation highlighting the input datasets, processing methods, data characteristics, and validation results based on a selected set of NGA geodetic control points. Distribution of this new dataset is expected later this year. Following the commencement of the public release, the products will undergo another thorough accuracy assessment using additional control data and will include an evaluation of other continents using ICESat altimetry data.

For this paper, we have assessed the agreement between ICESat centroid and ground elevations (essentially the same for narrow waveform returns) at the ICESat footprint location, and produced estimates of the differences based on land cover and relief for four of the layers in the GMTED2010 product. Those layers are the Mean and Median for the 15 arcsecond resolution, and the Mean and Systematic Discrete Subsample products for the 30 arc-second resolution. The mean and median products are computed using all cells from the higher resolution source data that are located within the lower resolution GMTED2010 cell. The discrete subsample elevation is that of the source data cell at the center of the GMTED2010 cell. The GMTED2010 products were provided in geographic coordinates referenced to the WGS- 84 
horizontal datum, with the horizontal coordinates expressed in decimal degrees. The elevation values are integer meters, referenced in most cases to the EGM96 geoid as the vertical datum, but for sources other than SRTM or SPOT 5 Reference3D data, the vertical datum varies according to the source data and no vertical datum adjustments were performed. Where the SRTM data was the primary higher resolution data source, each 30-arc-second pixel has been generalized from 9001 -arc-second SRTM pixels ( 30 by 30 cells). One 30 -arc-second pixel is spatially coincident with four 15-arc-second pixels, and each 15-arc-second pixel is coincident with four 7.5-arc-second pixels. Data characteristics such as the projection system, coordinate units, and horizontal and vertical datum vary among the input data sources. With the exception of the vertical datum, these input data characteristics were systematically converted to a consistent set of parameters prior to the generalization and creation of the global seamless elevation dataset.

Since the ICESat elevations are distributed with respect to the Topex/Poseidon ellipsoid, ICESat elevations were converted to the WGS-84 ellipsoid and the EGM96 geoid corrections were applied in order to evaluate the GMTED2010 products. Although the vertical datum differences between the input data sources were not transformed in the GMTED2010 products, the effects on mean biases that may result from these discrepancies have not precluded this dataset from performing well below their accuracy requirements. The elevation differences between the ICESat data selected for ground control and selected GMTED2010 product layers (Discrete Subsample, Mean, and Median) were computed, and statistics compiled.

\section{PRELIMINARY EVALUATION OF GMTED2010 PRODUCTS FOR AUSTRALIA}

\subsection{GMTED2010 Data Sources in Australia}

The primary source dataset for the new global model in Australia is NGA's Shuttle Radar Topography Mission (SRTM) DTED®2 (void-filled) 1-arc-second data ${ }^{[3,16]}$. These data covers approximately $80 \%$ of the Earth's land surface (between $60^{\circ} \mathrm{N}$ and $56^{\circ} \mathrm{S}$ ), and represents a significant upgrade to the source data included in the GTOPO30 elevation data $^{[11]}$. The void-filled SRTM data used in the production of these data are a revised version that is not currently publicly available. In addition to the voids being filled, the dataset contains further data editing not included in the original release $\mathrm{e}^{[16]}$. The void fill process was done such that it closely follows the trend of the original SRTM surface while retaining the useful characteristics from the source fill data. There were three main causes for voids in the SRTM data: a few patches of land in North America missed because the radar sensor did not collect data during 10 orbits of the mission, shadow and layover effects caused by steep slopes, and poor radar returns from certain areas with sandy soils (e.g. northern Africa $)^{[3]}$. The voids in the SRTM dataset for Australia were filled using the GeoData 9-Arc-Second bare earth product produced by Geoscience Australia prior to generalization (see Figure 9 in $^{[11]}$ ) $^{[17]}$.

For this preliminary analysis we do not have information in the form of a flag that can help us assess elevation biases based on source data. Therefore, all statistics are shown based on the differences with respect to ICESat elevations minus the GMTED2010 DEM at the various resolutions independent of source data. In addition, we have performed a comparison between ICESat and an earlier version of the "finished" SRTM data (v2.0), publically available from the EROS Data Center, which is provided with the ICESat products.

\section{RESULTS}

\subsection{Differences between ICESat, SRTM and GMTED2010}

The Australia ICESat GCP data selected by our editing for one representative observation period is shown in Figure 2, plotting differences between the ICESat centroid and GMTED2010. Also shown are elevation difference distributions for representative ICESat observation periods acquired with Laser 2 and Laser 3. Differences between ICESat and the various elevation products exhibit normal distributions centered about the mean. Table 2 shows the difference statistics for a representative laser period between the four waveform-derived ICESat elevations and the SRTM product at $90 \mathrm{~m}$ resolution, and GMTED2010 products for the 15 arc-second and 30 arc-second resolutions. Differences with respect to the ground are very similar to those for the centroid for the narrow waveforms selected for our GCP database; the difference between the highest and lowest elevation differences correspond to the mean pulse width in the GCP dataset. 

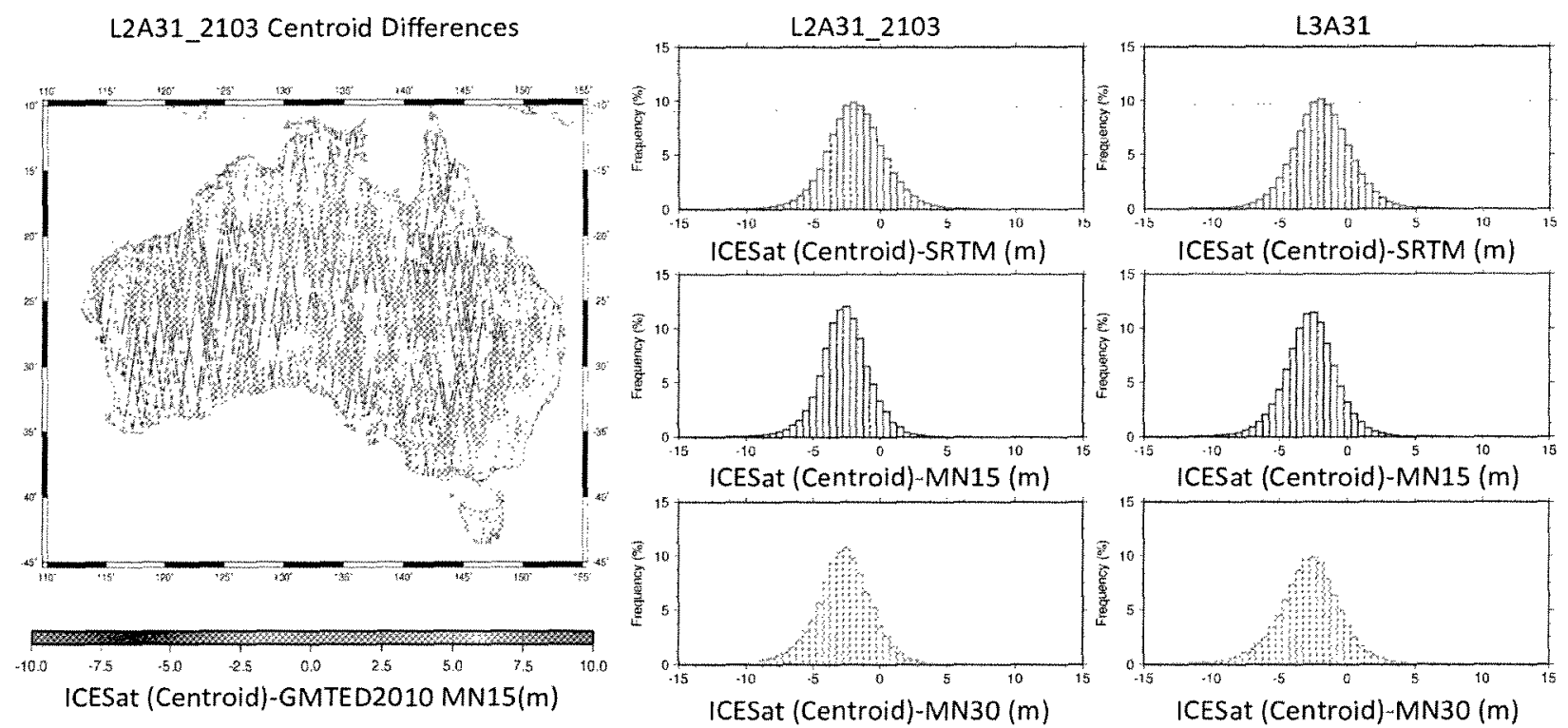

Fig. 2. Map of elevation differences between the L2B ICESat period GCPs and the GMTED2010 mean 15 arc-second product, scaled between -10 and $10 \mathrm{~m}$, and histogram distributions of the ICESat centroid elevation differences with the finished SRTM data on the ICESat product (red), the 15" Mean (blue) and 30" Mean (green) GMTED products using GCPs from the L2A and L3A observation periods.

When the high resolution source elevation data were generalized to the reduced resolution GMTED2010 products values representing the mean, median and discrete sample elevations from the full resolution source data were assigned to the center of the GMTED2010 cells,. Systematic sub-samples of the full resolution data were computed using a resample function which attributes the lower resolution cell with the nearest neighbor elevation from the higher resolution source ${ }^{[12]}$. Figure 3 shows statistics of the differences between ICESat GCP elevations from all laser 2 and 3 periods with respect to SRTM and theGMTED2010 Mean 15 arc-seconds and 30 arc-seconds DEMs for Australia. For comparisons between ICESat ground elevations (and similarly for centroid elevations for narrow waveforms), there is a systematic mean bias of about $2 \mathrm{~m}$ for SRTM with respect to ICESat elevation, with SRTM being higher. The negative bias is about $3 \mathrm{~m}$ for the GMTED2010 datasets of which the mean and median 15 arc-second products are shown in Figure 3 . The 30 arc-second GMTED2010 topography is slightly higher in a mean sense than the 15 arc-second dataset by about $25 \mathrm{~cm}$, at least at the location and time for the selected laser returns. These mean biases decrease slightly through time with decreasing laser energy, especially for Laser 2 . If we do not take the two very low energy Laser 2 periods into account (2D and $2 \mathrm{E}$ ), the variability of the differences between ICESat ground elevations and the 5 global DEMs does not vary by more than 0.5 meter across all laser periods.

The other statistics shown here (standard deviations and RMSE) are stable through all laser periods, despite the disparities in the number of edited shots (about 100,000 for L2A, with large editing of saturated returns during this high energy period, to almost 500,000 for L2C and L3I), with L2E being an exception. Therefore, we speculate that ICESat inter-period biases are possibly correlated with decay in laser energy that led to lowering of the waveform processing thresholds. Also differential geographic sampling may have introduced between period-biases due to selective exclusion of returns from relatively brighter surfaces during the early periods with extensive waveform saturation. In contrast, during low energy periods areas with relatively dark surfaces yielding weak returns would be selectively excluded. Because SRTM, and therefore also GMTED2010, have spatially coherent, long-wavelength error undulations relative to our GCP control ${ }^{[6]}$ differential geographic sampling could introduce the small between-period biases. Since SRTM is the primary source in GMTED2010 the difference in mean biases relative to the ICESat GCPs, with the GMTED2010 products nearly one meter above SRTM, is unexpected. We infer that in the generalization process to lower resolution, in addition to an increase in the standard deviations of the elevation differences, the upward bias in GMTED2010 is introduced because all source SRTM cells are used including those displaced upward by vegetation cover ${ }^{[4,5]}$. Our use of narrow width GCPs means that our assessment of the $90 \mathrm{~m}$ SRTM product is done only at footprint locations with 
minimal vegetation cover, whereas for GMTED210 vegetated areas become incorporated in the generalized cell elevations. Examination of elevation difference maps (e.g. Figure 2) show that the greatest upward bias in GMTED210 occurs in coastal areas with forest cover, consistent with our inference.

Table 2. Differences between ICESat and SRTM and GMTED products for Median and Mean at 15 arc-second resolution and Discrete Sample and Mean at 30 arc-second resolution for a representative Laser period (L3C) indicating the number of returns and the mean, standard deviation and RMSE of the differences with respect to ICESat "s centroid and ground (nearly the same for narrow returns) and the highest and lowest surfaces observed.

\begin{tabular}{|l|l|l|l|l|}
\hline Australia L3C31 (WGS84-EGM96) ICESat - Product Differences (m) \\
\hline SRTM & NP & MEAN & STDV & RMSE \\
\hline Centroid & 387123 & -1.97 & 2.22 & 2.96 \\
\hline High & 387123 & 0.11 & 2.23 & 2.23 \\
\hline Low & 387123 & -3.94 & 2.22 & 4.52 \\
\hline Ground & 387123 & -1.96 & 2.22 & 2.96 \\
\hline md15 (Median at 15") & NP & MEAN & STDV & RMSE \\
\hline Centroid & 387123 & -2.76 & 2.15 & 3.50 \\
\hline High & 387123 & -0.68 & 2.16 & 2.26 \\
\hline Low & 387123 & -4.73 & 2.15 & 5.20 \\
\hline Ground & 387123 & -2.75 & 2.15 & 3.50 \\
\hline mn15(Mean at 15") & NP & MEAN & STDV & RMSE \\
\hline Centroid & 387123 & -2.80 & 2.19 & 3.55 \\
\hline High & 387123 & -0.72 & 2.19 & 2.31 \\
\hline Low & 387123 & -4.77 & 2.19 & 5.25 \\
\hline Ground & 387123 & -2.79 & 2.19 & 3.55 \\
\hline ds30 (Discrete Sample at 30") & NP & MEAN & STDV & RMSE \\
\hline Centroid & 387123 & -2.85 & 3.58 & 4.58 \\
\hline High & 387123 & -0.77 & 3.59 & 3.67 \\
\hline Low & 387123 & -4.82 & 3.58 & 6.01 \\
\hline Ground & 387123 & -2.84 & 3.59 & 4.58 \\
\hline mn30 (Mean at 30") & NP & MEAN & STDV & RMSE \\
\hline Centroid & 387123 & -2.89 & 2.95 & 4.13 \\
\hline High & 387123 & -0.81 & 2.95 & 3.06 \\
\hline Low & 387123 & -4.86 & 2.95 & 5.69 \\
\hline Ground & 387123 & -2.88 & 2.95 & 4.13 \\
\hline
\end{tabular}

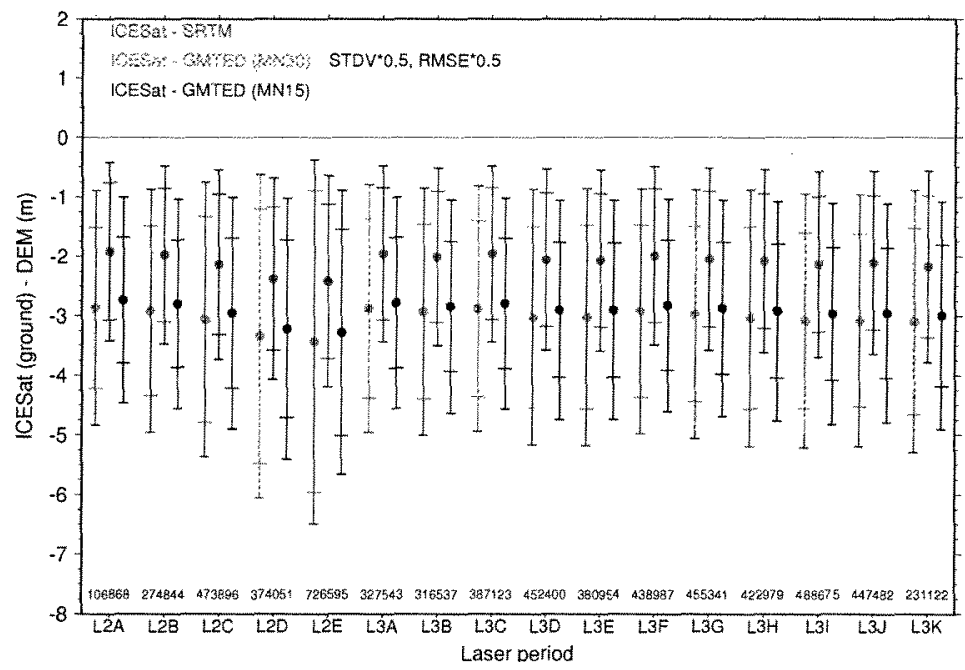

Fig. 2. Elevation differences between the ICESat GCP ground elevations and the SRTM $90 \mathrm{~m}$ product (red) and the GMTED2010 mean products at 30 arc-second (green) and 15 arc-second (blue) resolutions. The number of observations per ICESat laser period used is noted at the bottom. The standard deviations and the RMSE values have been multiplied by 0.5 in order to expand the $y$-axis to enhance the small inter-campaign biases. 
Table 3. Differences between the ICESat GCP centroids and SRTM and GMTED products for Discrete Sample and Mean at 30 arc-second (ds30 and mn30, respectively), and Median and Mean (md15 and mn15, respectively) at 15 arc-second resolution for all Laser 2 and 3 periods indicating the number of GCPs used (NP), and the means, standard deviations and RMSEs of the differences in meters.

\begin{tabular}{|c|c|c|c|c|c|c|c|c|c|}
\hline \multicolumn{5}{|c|}{ ICESat Period } & \multicolumn{5}{|c|}{ ICESat Period } \\
\hline L2A31 2103 & NP & MEAN & STDV & RMSE & L3D & NP & MEAN & STDV & RMSE \\
\hline SRTM & 106868 & -1.86 & 2.31 & 2.96 & SRTM & 452400 & -2.07 & 2.24 & 3.05 \\
\hline ds30 & 106868 & -2.75 & 3.24 & 4.25 & ds 30 & 452400 & -2.97 & 3.65 & 4.70 \\
\hline mn30 & 106868 & -2.81 & 2.71 & 3.90 & $\mathrm{mn} 30$ & 452400 & -3.03 & 3.04 & 4.29 \\
\hline md15 & 106868 & -2.65 & 2.09 & 3.38 & md15 & 452400 & -2.87 & 2.23 & 3.63 \\
\hline $\mathrm{mn} 15$ & 106868 & -2.68 & 2.11 & 3.41 & $\mathrm{mn15}$ & 452400 & -2.91 & 2.26 & 3.68 \\
\hline L2B & NP & MEAN & STDV & RMSE & L3E & NP & MEAN & STDV & RMSE \\
\hline SRTM & 274844 & -1.96 & 2.24 & 2.98 & SRTM & 380954 & -2.08 & 2.24 & 3.05 \\
\hline ds30 & 274844 & -2.85 & 3.39 & 4.42 & ds 30 & 380954 & -2.98 & 3.69 & 4.74 \\
\hline $\operatorname{mn} 30$ & 274844 & -2.90 & 2.85 & 4.07 & mn30 & 380954 & -3.03 & 3.08 & 4.32 \\
\hline md15 & 274844 & -2.75 & 2.09 & 3.46 & md15 & 380954 & -2.88 & 2.20 & 3.62 \\
\hline mn15 & 274844 & -2.78 & 2.13 & 3.51 & mn15 & 380954 & -2.92 & 2.25 & 3.69 \\
\hline $\mathrm{L} 2 \mathrm{C}$ & NP & MEAN & STDV & RMSE & $\mathbf{L 3 F}$ & NP & MEAN & STDV & RMSE \\
\hline SRTM & 473896 & -2.11 & 2.36 & 3.16 & SRTM & 438987 & -2.00 & 2.25 & 3.01 \\
\hline ds30 & 473896 & -2.97 & 4.03 & 5.00 & ds 30 & 438987 & -2.90 & 3.47 & 4.52 \\
\hline $\mathrm{mn30}$ & 473896 & -3.03 & 3.44 & 4.59 & $\operatorname{mn} 30$ & 438987 & -2.94 & 2.89 & 4.12 \\
\hline md15 & 473896 & -2.88 & 2.47 & 3.79 & md15 & 438987 & -2.80 & 2.14 & 3.52 \\
\hline mn15 & 473896 & -2.92 & 2.52 & 3.85 & $\operatorname{mn} 15$ & 438987 & -2.84 & 2.18 & 3.58 \\
\hline L2D & $\mathrm{NP}$ & MEAN & STDV & RMSE & $\mathrm{L} 3 \mathrm{G}$ & $\mathbf{N P}$ & MEAN & STDV & RMSE \\
\hline SRTM & 374051 & -2.34 & 2.40 & 3.36 & SRTM & 455341 & -2.06 & 2.28 & 3.07 \\
\hline ds30 & 374051 & -3.25 & 4.93 & 5.91 & ds30 & 455341 & -2.93 & 3.52 & 4.58 \\
\hline mn30 & 374051 & -3.31 & 4.27 & 5.40 & $\operatorname{mn} 30$ & 455341 & -2.98 & 2.94 & 4.19 \\
\hline md15 & 374051 & -3.12 & 2.89 & 4.25 & md15 & 455341 & -2.85 & 2.17 & 3.58 \\
\hline $\mathrm{mn} 15$ & 374051 & -3.18 & 2.96 & 4.35 & $\mathrm{mn15}$ & 455341 & -2.88 & 2.21 & 3.63 \\
\hline $\mathrm{L} 2 \mathrm{E}$ & NP & MEAN & STDV & RMSE & L3H & NP & MEAN & STDV & RMSE \\
\hline SRTM & 726595 & -2.41 & 2.59 & 3.54 & SRTM & 422979 & -2.09 & 2.26 & 3.08 \\
\hline ds30 & 726595 & -3.34 & 5.72 & 6.62 & ds 30 & 422979 & -2.99 & 3.67 & 4.73 \\
\hline mn30 & 726595 & -3.42 & 5.06 & 6.11 & $\mathrm{mn30}$ & 422979 & -3.05 & 3.05 & 4.31 \\
\hline md15 & 726595 & -3.20 & 3.36 & 4.64 & md15 & 422979 & -2.89 & 2.20 & 3.63 \\
\hline mn15 & 726595 & -3.27 & 3.46 & 4.76 & $\operatorname{mn15}$ & 422979 & -2.93 & 2.24 & 3.69 \\
\hline $\mathbf{L 3 A}$ & NP & MEAN & STDV & RMSE & L3I & NP & MEAN & STDV & RMSE \\
\hline SRTM & 327543 & -1.95 & 2.22 & 2.95 & SRTM & 488675 & -2.15 & 2.27 & 3.13 \\
\hline ds30 & 327543 & -2.83 & 3.57 & 4.55 & ds 30 & 488675 & -3.05 & 3.53 & 4.66 \\
\hline mn30 & 327543 & -2.87 & 3.01 & 4.16 & mn30 & 488675 & -3.10 & 2.95 & 4.28 \\
\hline md15 & 327543 & -2.74 & 2.15 & 3.48 & md15 & 488675 & -2.95 & 2.19 & 3.68 \\
\hline $\operatorname{mn} 15$ & 327543 & -2.78 & 2.20 & 3.54 & mn15 & 488675 & -2.99 & 2.23 & 3.73 \\
\hline L3B & NP & MEAN & STDV & RMSE & L3J & NP & MEAN & STDV & RMSE \\
\hline SRTM & 316537 & -2.01 & 2.20 & 2.98 & SRTM & 447482 & -2.13 & 2.25 & 3.09 \\
\hline ds30 & 316537 & -2.88 & 3.51 & 4.54 & ds30 & 447482 & -3.04 & 3.47 & 4.61 \\
\hline mn30 & 316537 & -2.93 & 2.93 & 4.14 & $\operatorname{mn} 30$ & 447482 & -3.10 & 2.89 & 4.24 \\
\hline md15 & 316537 & -2.80 & 2.15 & 3.53 & md15 & 447482 & $-2,93$ & 2.15 & 3.63 \\
\hline mn15 & 316537 & -2.84 & 2.18 & 3.58 & $\operatorname{mn} 15$ & 447482 & -2.97 & 2.18 & 3.69 \\
\hline L3C & $\mathbf{N P}$ & MEAN & STDV & RMSE & L3K & NP & MEAN & STDV & RMSE \\
\hline SRTM & 387123 & -1.97 & 2.22 & 2.96 & SRTM & 231122 & -2.20 & 2.37 & 3.23 \\
\hline $\mathrm{ds} 30$ & 387123 & -2.85 & 3.58 & 4.58 & ds 30 & 231122 & -3.08 & 3.68 & 4.80 \\
\hline $\mathrm{mn30}$ & 387123 & -2.89 & 2.95 & 4.13 & mn30 & 231122 & -3.12 & 3.13 & 4.42 \\
\hline md15 & 387123 & -2.76 & 2.15 & 3.50 & md15 & 231122 & -2.98 & 2.34 & 3.79 \\
\hline $\mathrm{mn} 15$ & 387123 & -2.80 & 2.18 & 3.55 & $\mathrm{mn} 15$ & 231122 & -3.02 & 2.37 & 3.84 \\
\hline
\end{tabular}

\subsection{Differences with respect to Land Cover}

We examined the elevation differences with respect to land cover using the classification provided by the regional Glocover data ${ }^{[10]}$. The GCP frequency as a function of class is shown in Figure 4 along with plots of the mean differences and standard deviations for each class for a representative ICESat period. Table 4 shows the statistics for the same period for the 15 arc-second products. 

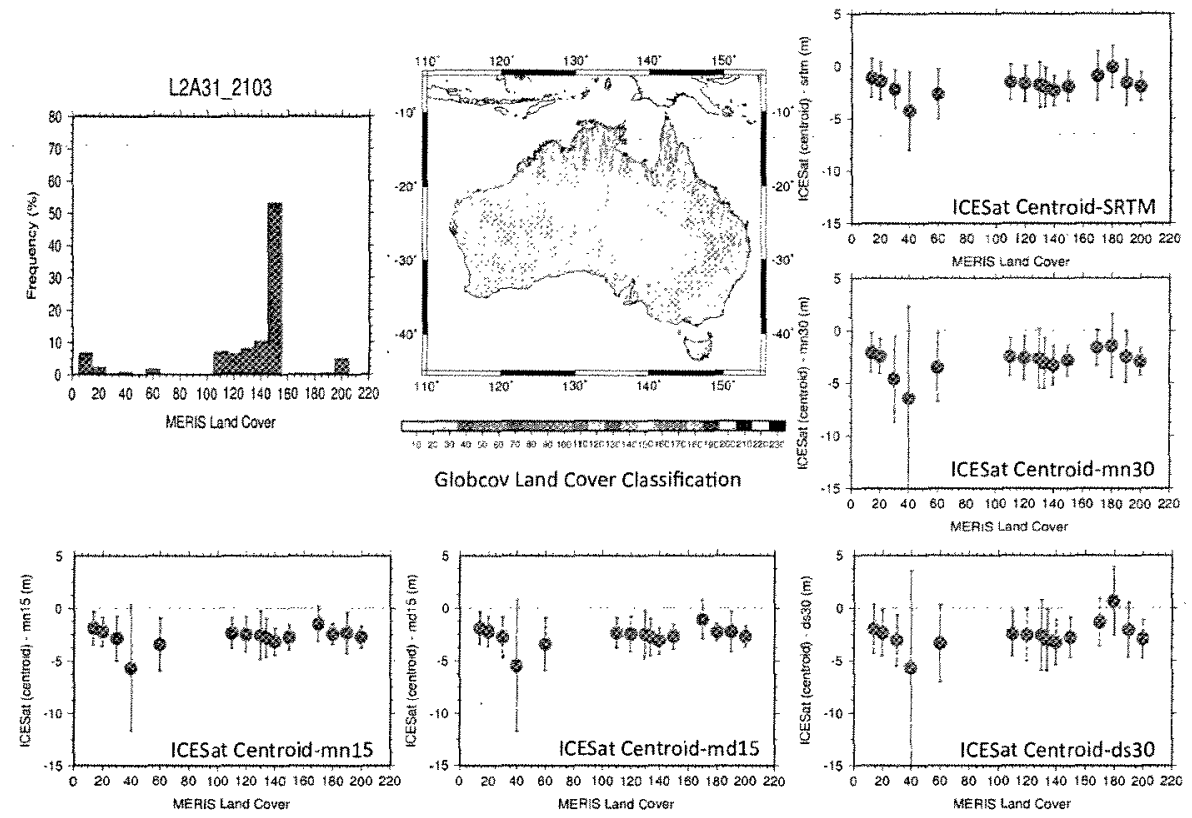

Fig. 4. Results for L2A GCP centroid elevation differences as a function of land cover class, with GCP frequencies per class (top left), a map of cover class at the GCP locations (top center) and plots of mean differences and standard deviations per class for the 15 arc-second Mean (mn15) and Median (md15), and the 30 arc-second Mean (mn30) and Discrete Sample (ds30) GMTED2010 products and the SRTM $90 \mathrm{~m}$ product.. The land cover classes are defined in Table 6.

Table 4. Statistics number of points (NP) for differences between ICESat centroid elevations and GMTED2010 as a function of land cover at the GCP locations for laser period L2A, for two of the products evaluated: $\mathrm{mn} 15=$ Mean at 15 " resolution (mn 15) and Median at 15" resolution (md15). See Table 6 for Land Cover Classes [LC Class] definitions.

\begin{tabular}{|c|c|c|c|c|c|c|c|c|}
\hline ICESat L A - GMTED2010 Elevation Differences with Respect to Land Cover \\
\hline Product & mn15 & \multicolumn{1}{|c|}{ 15" Mean } & md15 & \multicolumn{1}{l|}{ 15" Median } \\
\hline LC Class & Mean & STDV & RMSE & NP & Mean & STDV & RMSE & NP \\
\hline 14 & -1.92 & 1.59 & 2.96 & 13922 & -1.87 & 1.56 & 2.89 & 13922 \\
\hline 20 & -2.25 & 1.39 & 2.99 & 4350 & -2.22 & 1.41 & 2.98 & 4350 \\
\hline 30 & -2.86 & 2.11 & 4.13 & 126 & -2.71 & 1.94 & 3.86 & 126 \\
\hline 40 & -5.69 & 6.01 & 10.23 & 1096 & -5.50 & 6.24 & 10.40 & 1096 \\
\hline 60 & -3.44 & 2.51 & 4.94 & 3142 & -3.40 & 2.52 & 4.92 & 3142 \\
\hline 110 & -2.35 & 1.46 & 3.13 & 14846 & -2.33 & 1.45 & 3.11 & 14846 \\
\hline 120 & -2.48 & 1.67 & 3.42 & 13490 & -2.43 & 1.65 & 3.37 & 13490 \\
\hline 130 & -2.56 & 2.30 & 4.14 & 10836 & -2.53 & 2.25 & 4.07 & 10836 \\
\hline 134 & -2.81 & 1.83 & 3.82 & 6128 & -2.76 & 1.76 & 3.72 & 6128 \\
\hline 140 & -3.16 & 1.28 & 3.64 & 21590 & -3.14 & 1.26 & 3.61 & 21590 \\
\hline 150 & -2.72 & 1.20 & 3.20 & 113232 & -2.69 & 1.19 & 3.17 & 113232 \\
\hline 170 & -1.48 & 1.68 & 2.80 & 204 & -1.07 & 1.87 & 2.85 & 204 \\
\hline 180 & -2.44 & 0.99 & 2.81 & 18 & -2.21 & 0.82 & 2.50 & 18 \\
\hline 190 & -2.34 & 1.97 & 3.63 & 508 & -2.24 & 1.91 & 3.51 & 508 \\
\hline 200 & -2.72 & 1.03 & 3.08 & 10246 & -2.69 & 1.01 & 3.04 & 10246 \\
\hline
\end{tabular}


Table 5. Same as Table 4, but for GMTED2010 Discrete Sample at 30" resolution (ds30) and Mean at 30" resolution (mn30) products.

\begin{tabular}{|c|c|c|c|c|c|c|c|c|}
\hline ICESat L2A - GMTED2010 Elevation Differences with Respect to Land Cover \\
\hline Product & ds30 & 30" Discrete Sample & \multicolumn{1}{|c|}{ mn30 } & \multicolumn{3}{|l|}{ 30" Mean } \\
\hline LC Class & Mean & STDV & RMSE & NP & Mean & STDV & RMSE & NP \\
\hline 14 & -1.97 & 2.35 & 3.86 & 13922 & -2.07 & 1.86 & 3.35 & 13922 \\
\hline 20 & -2.36 & 2.17 & 3.87 & 4350 & -2.42 & 1.66 & 3.37 & 4350 \\
\hline 30 & -3.06 & 2.42 & 4.59 & 126 & -4.60 & 4.13 & 7.44 & 126 \\
\hline 40 & -5.70 & 9.27 & 14.30 & 1096 & -6.43 & 8.72 & 13.91 & 1096 \\
\hline 60 & -3.35 & 3.66 & 6.17 & 3142 & -3.48 & 3.27 & 5.79 & 3142 \\
\hline 110 & -2.44 & 2.14 & 3.89 & 14846 & -2.49 & 1.83 & 3.59 & 14846 \\
\hline 120 & -2.56 & 2.44 & 4.30 & 13490 & -2.59 & 2.12 & 3.96 & 13490 \\
\hline 130 & -2.57 & 3.34 & 5.38 & 10836 & -2.65 & 2.83 & 4.80 & 10836 \\
\hline 134 & -3.02 & 2.91 & 5.11 & 6128 & -3.09 & 2.43 & 4.62 & 6128 \\
\hline 140 & -3.24 & 2.14 & 4.44 & 21590 & -3.30 & 1.90 & 4.26 & 21590 \\
\hline 150 & -2.78 & 1.91 & 3.87 & 113232 & -2.82 & 1.50 & 3.53 & 113232 \\
\hline 170 & -1.35 & 2.27 & 3.48 & 204 & -1.62 & 1.72 & 2.92 & 204 \\
\hline 180 & 0.68 & 3.25 & 4.65 & 18 & -1.44 & 3.03 & 4.52 & 18 \\
\hline 190 & -2.04 & 2.59 & 4.20 & 508 & -2.45 & 2.48 & 4.28 & 508 \\
\hline 200 & -2.88 & 1.82 & 3.87 & 10246 & -2.91 & 1.30 & 3.45 & 10246 \\
\hline
\end{tabular}

Table 6. Definition of the 22 Level 1 Globcover classes used in this analysis.




The lowest standard deviations occur for bare areas, with mean differences of $-2.88 \mathrm{~m} \pm 1.82 \mathrm{~m}$ and $3.87 \mathrm{~m}$ RMS for the Mean 15 arc-second products, and $-2.91 \pm 1.30 \mathrm{~m}$ and RMSE of $3.45 \mathrm{~m}$ for the Median 15 arc-second product (Table 4). Larger negative mean differences (GMTED higher) are observed for vegetated classes. The mean differences and standard deviations are consistent with the vegetation height and density of the classes. For the Mean and Median 15 arc-second products, the largest mean differences $(-5.69 \mathrm{~m} \pm 6.01 \mathrm{~m}$ and $-5.50 \pm 6.24 \mathrm{~m})$ are observed for closed to open $(>15 \%)$ broadleaved evergreen or semi-deciduous forest $(>5 \mathrm{~m})$ (Table 4). Similar statistics are shown for the Discrete Sample and Mean products at 30 arc-second resolution, with means of $-5.70 \mathrm{~m} \pm 9.27 \mathrm{~m}$ and an RMSE of $14.30 \mathrm{~m}$ and means of $-6.43 \pm 8.72 \mathrm{~m}$, and an RMSE of $13.91 \mathrm{~m}$, respectively (Table 5). The largest represented class (113,232 GCPs), corresponding to sparse $(<15 \%)$ vegetation, has smaller elevation differences and standard deviations than the forest class, with mean differences of $-2.72 \mathrm{~m} \pm 1.20 \mathrm{~m}$ and a $3.20 \mathrm{~m} \mathrm{RMSE}$, and $-2.69 \pm 1.19 \mathrm{~m}$ with a $3.17 \mathrm{~m}$ RMSE for Mean and Median products, respectively The lower resolution products show $-2.78 \pm 1.91$ with a RMSE of $3.87 \mathrm{~m}$ and $-2.82 \pm 1.50 \mathrm{~m}$ with RMSE of $3.53 \mathrm{~m}$ (Table 5). These differences as a function of class vegetation height and density are consistent with our inference that the upward bias of SRTM caused by vegetation is being introduced by generalization into the GMTED products.

\subsection{Differences with Respect to Relief}

Relief at the location of the ICESat GCPs was computed using the standard deviation of the SRTM (V2.0) elevations for the $3 \times 3$ array of cells (at $90 \mathrm{~m}$ resolution) that include and surround the footprint geolocation. For the selected GCPs, most of the relief is less than $5 \mathrm{~m}$. Frequency distributions of relief binned at $0.5 \mathrm{~m}$ for all the periods analyzed show that most of the GCPs occur into the 3.5 to $4.5 \mathrm{~m}$ relief categories. Statistics for the various relief categories are shown in Table 7 for the SRTM, and GMTED2010 Mean and Median products at 15 arc-second resolution using the Laser 3C period GCPs. Table 8 shows those statistics for the Mean and Discrete Sample GMTED2010 products at 30 arc-second resolution, while Figure 5 shows (top right) the relief category frequencies of occurrence. The distributions for ICESat minus SRTM are also shown for comparison. For all cases, means and standard deviations are consistent, with SRTM mean differences showing smaller means by approximately $1 \mathrm{~m}$ with respect to the GMTED2010 products, all of them higher with respect to ICESat centroid elevations. The largest negative means are observed for the relief category between 2 and $2.5 \mathrm{~m}$, which also shows the largest standard deviations on the order of $2 \mathrm{~m}$ with RMSEs of approximately $4 \mathrm{~m}$. However, there is no trend as a function of relief and the differences in the mean biases for the relief categories is very small, less than about $1 \mathrm{~m}$.

Table 7. Statistics for the differences by relief category between ICESat centroid elevations and SRTM and GMTED2010 Mean and Median 15 arc-second products (MN15 and MD15, respectively) for the L3C period.

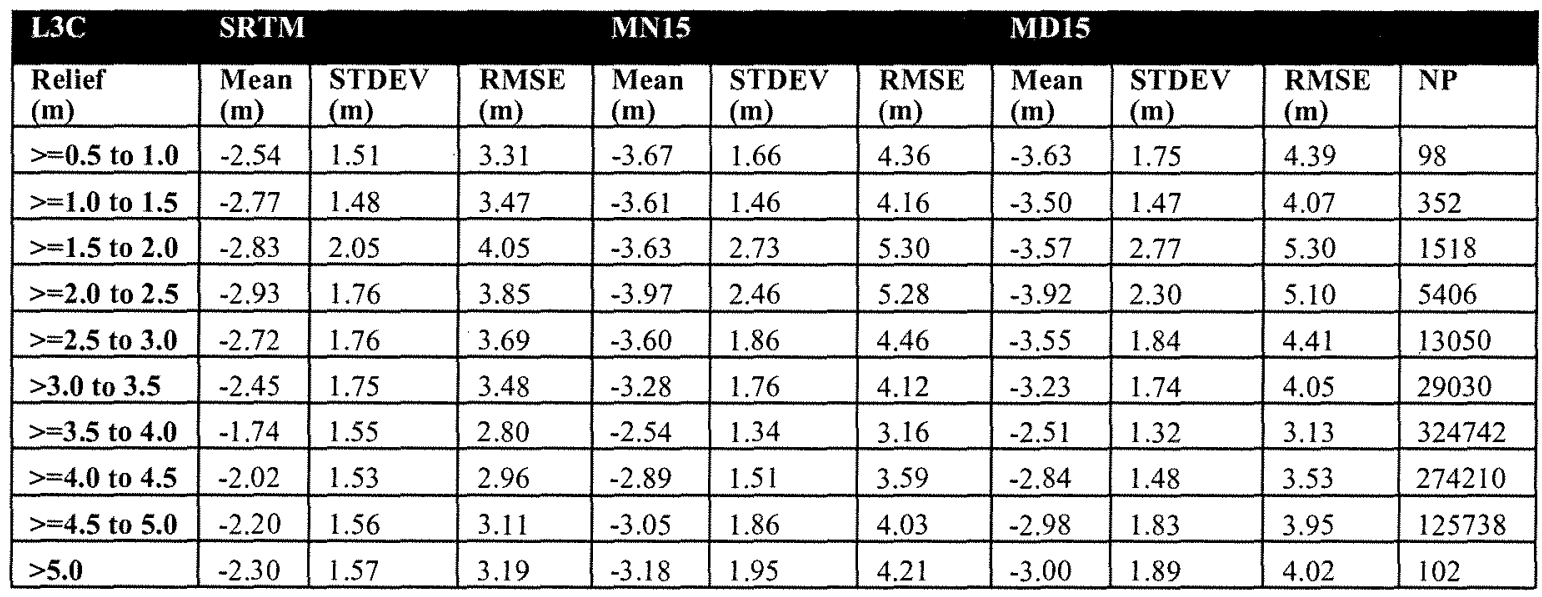


Table 8. Statistics for the differences by relief between ICESat centroid elevations and GMTED2010 Mean and Discreet Sample 30 arc-second products (MN30 and DS30, respectively) for the L3C period.

\begin{tabular}{|c|c|c|c|c|c|c|c|}
\hline L3C & MN30 & & & DS30 & & & \\
\hline $\begin{array}{l}\text { Relief } \\
(\mathrm{m})\end{array}$ & $\begin{array}{l}\text { Mean } \\
(\mathrm{m})\end{array}$ & $\begin{array}{l}\text { STDEV } \\
(\mathrm{m})\end{array}$ & $\begin{array}{l}\text { RMSE } \\
(\mathbf{m})\end{array}$ & $\begin{array}{l}\text { Mean } \\
(\mathrm{m})\end{array}$ & $\begin{array}{l}\text { STDEV } \\
\text { (m) }\end{array}$ & $\begin{array}{l}\text { RMSE } \\
(\mathrm{m})\end{array}$ & NP \\
\hline$>=0.5$ to 1.0 & -3.67 & 2.12 & 4.74 & -3.18 & 2.50 & 4.75 & 98 \\
\hline$>=1.0$ to 1.5 & -4.00 & 2.32 & 5.17 & -3.59 & 2.77 & 5.31 & 352 \\
\hline$>=1.5$ to 2.0 & -3.77 & 3.65 & 6.39 & -3.77 & 3.89 & 6.67 & 1518 \\
\hline$>=2.0$ to 2.5 & -4.05 & 3.35 & 6.23 & -4.07 & 4.47 & 7.52 & 5406 \\
\hline$>=2.5$ to 3.0 & -3.72 & 2.61 & 5.24 & -3.63 & 2.96 & 5.54 & 13050 \\
\hline$>3.0$ to 3.5 & -3.41 & 2.46 & 4.87 & -3.36 & 2.89 & 5.29 & 29030 \\
\hline$>=3.5$ to 4.0 & -2.61 & 1.67 & 3.52 & -2.58 & 2.10 & 3.93 & 324742 \\
\hline$>=4.0$ to 4.5 & -2.99 & 2.07 & 4.19 & -2.95 & 2.51 & 4.62 & 274210 \\
\hline$>=4.5$ to 5.0 & -3.12 & 2.68 & 4.91 & -3.08 & 3.19 & 5.47 & 125738 \\
\hline$>5.0$ & -3.20 & 2.74 & 5.02 & -3.14 & 2.87 & 5.13 & 102 \\
\hline
\end{tabular}
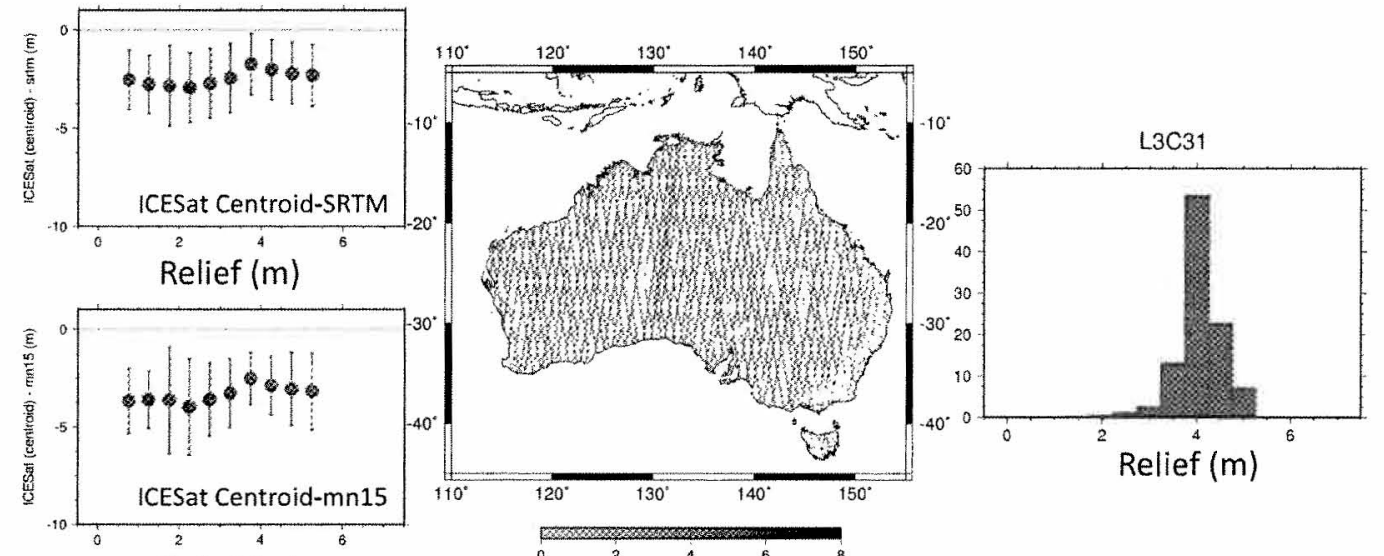

Relief (m)


Fig. 5. Elevation difference means and standard deviations as a function of relief category between the ICESat L3C GCP centroids and the SRTM $90 \mathrm{~m}$, and GMTED 2010 products for the mean and median at 15 arc-seconds (mn 15 and md15, respectively), and mean and discreet sample at 30 arc-seconds ( $\mathrm{mn} 30$ and ds 30 , respectively) The histogram shows the relief category frequencies of occurrence at $0.5 \mathrm{~m}$ binning.

Means, standard deviations and RMSEs are larger for the 15 arc-second products, with RMSEs not exceeding $5.3 \mathrm{~m}$ and as low as $3.13 \mathrm{~m}$. The largest represented category is relief between $3.5 \mathrm{~m}$ and $4 \mathrm{~m}$, with 324742 returns, where mean differences are the lowest for both 15 arc-second products, with a mean of $-2.54 \mathrm{~m}$, a standard deviation of $1.34 \mathrm{~m}$ and an RMSE of $3.16 \mathrm{~m}$ for the mean product, and a mean of $-2.51 \mathrm{~m}$, a standard deviation of $1.32 \mathrm{~m}$, and an RMSE of $3.13 \mathrm{~m}$. For the GMTED2010 30 arc-second resolution mean products, the most negative means are shown also for 2.0 to $2.5 \mathrm{~m}$ 
relief, with a standard deviation of $3.35 \mathrm{~m}$ and an RMSE of $6.23 \mathrm{~m}$. The largest mean and standard deviation for the Discrete Sample at 30 arc-second resolution are $-4.07 \mathrm{~m}$ and $4.47 \mathrm{~m}$, with a $7.52 \mathrm{~m}$ RMSE. The largest represented category with relief between $3.5 \mathrm{~m}$ and $4 \mathrm{~m}$ shows a mean of $-2.61 \mathrm{~m}$, a standard deviation of $1.67 \mathrm{~m}$ and RMSE of 3.52 $\mathrm{m}$ for the Mean product, and $-2.58 \mathrm{~m}, 2.1 \mathrm{~m}$ and $3.93 \mathrm{~m}$ for the Discrete Sample product.

\section{DISCUSSION AND CONCLUSIONS}

The ICESat laser altimetry data is an important contributor for global geodetic control of elevation data. It provides accurate and consistently reference geodetic quality data that can be used to assess the accuracy of DEMs, providing necessary information for studies where well understood error characteristics of terrain elevation data is required. Expanding on our prior work assessing the SRTM and GDEM data sets, we have quantified the error characteristics of the GMTED2010 elevation products for the Australian continent. Our analysis documents that the GMTED2010 products are a significant improvement over their predecessor GTOPO30 DEM, and provide new, systematically-derived global topographic data at resolutions appropriate for regional to continental applications where the higher resolution data sources are not necessary.

Prior to our work using ICESat, the GMTED2010 project evaluated the accuracy of the data set using a variety of reference data, including other raster DEMs and NGA control point datasets that are derived from photogrammetric sources. A complete data quality assessment for these products that includes a discrimination of biases by source data is presented in the documentation accompanying the dataset. As expected, the largest RMSEs are seen for those cells that were filled with GTOPO30 as the input source. Relevant to our analysis, since $90 \mathrm{~m}$ SRTM is the main source in Australia, is the absolute accuracy assessment performed for the $90 \mathrm{~m}$ SRTM source data compared with the NGA control. This shows a $2.37 \mathrm{~m}$ bias $\pm 15.91 \mathrm{~m}$ for the 15 arc-second mean product, and a $1.9 \mathrm{~m}$ bias $\pm 15.25 \mathrm{~m}$ for the Median product. The 30 arc-second Mean product showed a $4.0 \mathrm{~m}$ bias $\pm 26.12 \mathrm{~m}$, and a $3.51 \mathrm{~m}$ bias $\pm 25.06 \mathrm{~m}$ for the Systematic Discrete Subsample product. Our results yield mean biases of comparable magnitude, of a few meters, but dramatically smaller standard deviations that we attribute to the significantly higher accuracy ICESat GCPs, produced in a consistent, global reference frame. Use of the less accurate NGA control points leads to an erroneously high assessment of GMTED2010 error. It is only with control having accuracies substantially better than the data set to be evaluated that meaningful error assessments can be performed. Using the ICESat GCPs we have provided that assessment for the GMTED2010 Australian products, documenting that their errors are well within the requirements for the products, which were required to exceed the accuracy of GTOPO30.

In future work ICESat GCP data will be used to evaluate these products globally, providing assessments where other data for control purposes is scarce or of poor quality, in particular in northern and southern latitudes above and below $\pm 60^{\circ}$. This work developing the ICESat GCP dataset is contributing to a CEOS-sponsored project coordinating the development of a global, integrated elevation database produced from different sources, embedded into a consistent, high accuracy, and long-term stable geodetic reference frame. Our GCP database will be a key means to establish a muchneeded global topography reference frame to facilitate consistency and interoperability among DEM datasets. Our methodologies developed to use ICESat data for global geodetic control are a pathfinder for similar use of data to be produced by the follow-on ICESat-2 mission scheduled for launch in $2016^{[18]}$. ICESat-2 will provide substantially improved sampling as compared to ICESat, acquired using multi-beam, higher-resolution elevation data derived using an advanced micropulse, photon counting measurement approach. We are adapting our approach and developing new algorithms using simulated ICESat-2 datasets in order to take full advantage when this new global geodetic control data set becomes available.

\section{ACKNOWLEDGEMENTS}

This work was supported by NASA's Earth Surface and Interior (ESI) Program, Contract NNH09CF42C. "Building an ICESat Geodetic Control Data Base for Global Topographic Mapping and Solid Earth Studies." We thank our USGS collaborators for providing the GMTED2010 products in anticipation of their public release. 


\section{REFERENCES}

[1] Zwally, H.J., R. Schutz, W. Abdalati, J. Abshire, C. Bentley, J. Bufton, D. Harding, T. Herring, B. Minster, J, Spinhirne and R. Thomas, "ICESat's laser measurements of polar ice, atmosphere, ocean, and land," Journal of Geodynamics, 34(3-4), 405-445 (2002).

[2] Schutz, B. E., H. J. Zwally, C. A. Shuman, D. Hancock, and J. P. DiMarzio (2005), Overview of the ICESat Mission, Geophys. Res. Lett., 32, L21S01, doi:10.1029/2005GL024009 (2005).

[3] Farr, T. G., et al., "The Shuttle Radar Topography Mission," Rev. Geophys., 45, RG2004, doi: 10.1029/2005RG000183 (2007).

[4] Carabajal, C.C., and D. J. Harding, ICESat validation of SRTM C-band digital elevation models, Geophys. Res. Let.,32, L22S01, doi:10.1029/2005GL023957 (2005).

[5] Carabajal, C.C. and D. J. Harding, 2006, SRTM C-band and ICESat Laser Altimetry Elevation Comparisons as a Function of Tree Cover and Relief, Photogram. Eng. and Rem. Sens., 72(3), 287-298 (2006).

[6] Carabajal, C.C., D.J. Harding and V.P. Suchdeo, "ICESat Lidar and Global Digital Elevation Models: Applications to DESDynI," Proc. IEEE IGARSS '10 Symposium, Paper 4200, July 25-30, 2010, Honolulu, HI (2010).

[7] ASTER GDEM Validation Team: METI/ERSDAC, NASA/LPDAAC, USGS/EROS, in cooperation with NGA and Other Collaborators, "ASTER Global DEM Validation Summary Report," https://pdaac.usgs.gov/lpdaac/products/aster products table/routine/global digital elevation model/v1/astgtm (2009).

[8] Harding, D.J., and C.C. Carabajal, "ICESat Waveform Measurements of Within-footprint Topographic Relief and Vegetation Vertical Structure," Gephys. Res. Lett., L21S10, 10.1029/2005GL023471 (2005).

[9] S. Luthcke (private communication).

[10] http://www.esa.int/due/ionia/globcover; Source Data: (C ESA / ESA Globcover Project, led by MEDIASFrance/POSTEL).

[11] Danielson, J. J. and D. B. Gesch, "An Enhanced Global Elevation Model Generalized From Multiple Higher Resolution Source Datasets," Proc The International Archives of the Photogrammetry, Remote Sensing and Spatial Information Sciences Vol. XXXVII Part B4, 1857-1864 (2008).

[12] Danielson, Jeffrey J., and Gesch, Dean B., "Global Multi-resolution Terrain Elevation Data 2010 (GMTED2010): U.S. Geological Survey Open-File Report" (2011) (in press).

[13] Gesch, D.B., Verdin, K.L., and Greenlee, S.K., "New land surface digital elevation model covers the earth," EOS, Transactions, American Geophysical Union, v. 80, no. 6, p. 69-70 (1999).

[14] Harding, D.J., D. B Gesch, C. C. Carabajal, and S. B. Luthcke, "Application of the Shuttle Laser Altimeter in an accuracy assessment of GTOPO30, a global 1-kilometer digital elevation model." International Archives of Photogrammetry and Remote Sensing, 32, Part 3W14, $81-85$ (1999).

[15] Carabajal, C. C., D. H. Harding, S. B. Luthcke, W. Fong, S. C. Rowton and J.J. Frawley, "Processing of Shuttle Laser Altimeter Range and Return Pulse Data in support of SLA-02," Proc. of the ISPRS Workshop on "Mapping Surface Structure and Topography by Airborn and Spaceborn Lasers", 32, Part 3W14, 65-72 (1999).

[16] Slater, J.A., Garvey, G., Johnston, C., Haase, J., Heady, B., Kroenung, G, and Little, J., 2006, "The SRTM Data Finishing Process and Products," Photogrammetric Engineering and Remote Sensing, Vol. 772(3), 237-248 (2006).

[17] Geoscience Australia, http:/www.ga.gov.au/meta/ANZCW0703011541.html.

[18] Abdalati, W., H.J. Zwally, R, Bindschadler, B, Csatho, S.L. Farrell, H.A. Fricker, D. Harding, R. Kwok, M. Lefsky, T. Markus, A. Marshak, T. Neumann, S. Palm, B. Schutz, B. Smith, J. Spinhirne and C. Webb, "The ICESat-2 laser altimetry mission," Proc. IEEE 98(5), 735-751 (2010). 